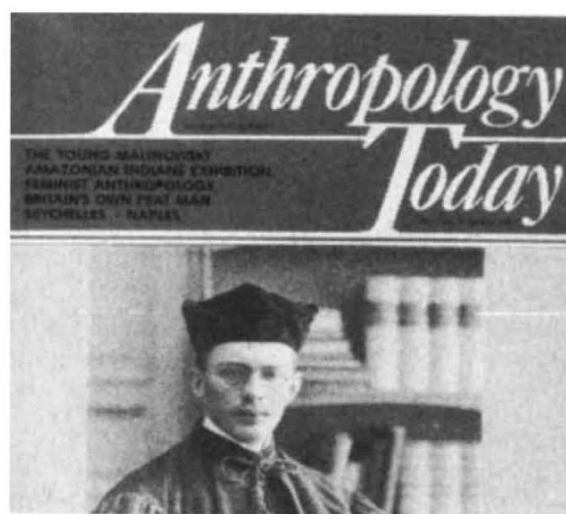

national's objection to the Museum of Mankind's exhibition on Amazonian Indians; the plight of the Miskitu Indians of Nicaragua; Christianity in China; child labour; and Hindu-Moslem confrontation are among the topics discussed in the issues that have appeared to date. Ethnographic films, a meeting-ground of anthropologists and the public, are a favourite subject for discussion and review. Study of other professions, and their interaction with anthropology, is exemplified in articles on development economics, clinical practice, psychiatry and body alteration.

It seems likely that Anthropology Today is, and will be, seriously and selectively read by anthropologists for their specialty: book reviews, reports of conferences, research and assessments of recent work in, for example, ceramics, feminist anthropology, human biology or religion. Obituaries and memoirs of anthropologists have been a rich field, especially in the centennial year of Malinowski's birth. Critical opinions stimulate response, correction and debate. The news of people, exhibitions, conferences, films, books, positions available fill one-quarter or more of the space, and there is also a UK insert (which I have not seen) for news of interest to readers in Britain.

Such a magazine is as interesting, selective or broad as its editors and contributors make it. Format and design are attractive, with scope for photographs, diagrams and maps. The language is non-technical, but not always lively. In its first year or two, even as a successor to a more limited periodical, it has the difficult task of finding a role valued by the profession and the public. However, there is no doubt that Anthropology Today does provide an informal, international forum for the varied interests and viewpoints of professional anthropologists and other commentators, unmatched in any other English-language publication. If it seems to be a bit of everything, and something for everyone, this may be a reflection of anthropology today.

Paula Brown Glick is Professor of Anthropolo gy, State University of New York, Stony Brook, New York 11794, USA.

\section{Simply the place to be seen?}

\author{
Warren R. Jones
}

Advances in Contraception. Editor-inchief G.I. Zatuchni. MTP Press. 4/yr. Dfl. $210, £ 52.50, \$ 86$.

RESEARCH and development in contraception, by and large, is in the doldrums. The majority of so-called "advances" in contraceptive technology are modifications of existing methods or attempts to improve their safety, acceptability and distribution. The contents of Advances in Contraception confirm this rather depressing outlook.

One of the four issues I received was wastefully devoted to abstracts of an annual meeting of the Society for the Advancement of Contraception, for whom the journal acts as official organ. Of the 27 articles in the other three issues, 23 were devoted to clinical studies or trials of contraceptive agents (12 on the IUD) and four were concerned with basic research in reproduction. Unless this emphasis changes, the journal will run the risk of limiting its readership to the professional purveyors of contraceptive trials, many of which are underwritten by pharmaceutical companies whose commercial capabilities are now, for the most part, restricted to keeping their products visible in the scientific and pseudoscientific literature. Advances in Contraception shows no evidence to date that it will attract contributions from researchers at the few sharp edges of contraceptive development.

On the plus side, the journal is well produced, with clear tables and half-tone figures. The abstracts are helpfully repeated in French and Spanish at the end of each paper; however the references are perversely numbered in sequence of appearance in the text. Reviews and letters are solicited but thus far only the former have appeared.

I suspect that Advances in Contraception has a preordained destiny that will allow it to survive the marketplace pressures on new scientific journals. The still vast international network of contraception-watchers will subscribe to, nurture and sustain it. For my part, I will economize in time and money and seek out one or two comprehensive reviews of clinical contraception every two or three years.

Warren R. Jones is Professor of Obstetrics and Gynaecology, Flinders Medical Centre, Bedford Park, South Australia 5042, Australia.

\section{Help from outside}

\section{C.R. Austin}

Journal of In Vitro Fertilization and Embryo Transfer. Editors-in-chief J. Friberg and N. Gleicher. Plenum. 6/yr. US $\$ 130$ (institutional), $\$ 49.50$ (individual); elsewhere $\$ 146$ (institutional), \$57.50 (individual).

Wiтн the phenomenal upsurge of interest and involvement in the production of "test-tube babies", the appearance of a highly specialized publication like the Journal of In Vitro Fertilization and Embryo Transfer was both justified and welcome. Beginning with four issues a year in 1984, it moved to six issues this year. Previously, most communications on the topic would have been offered to the Journal of Reproduction and Fertility, to Fertility and Sterility or to Biology of Reproduction, but there are clear advantages in gathering the material under one title.

The journal accepts original reports of basic or clinical investigations on human or animal subjects, as well as reviews and short communications. In general, a commendable standard has been maintained in the published papers, and one frequently sees names of workers known for their contributions in this field. A "News and
Views" section contains brief statements requiring rapid publication, as well as a most useful feature - a regular list of IVF-ET programmes recently "registered" with the central editorial office. Judging by the contents of the April 1986 issue, the journal also publishes (in the rather unsatisfactory camera-ready format) abstracts of papers read at appropriate conferences: thus in April, there were 82 abstracts from the Congress of Future Aspects in Human In Vitro Fertilization, held in Vienna in April 1986. Another important service is the organization of symposia specifically for the journal. The February 1986 issue contained papers making up one such symposium on "Embryo Freezing"; and a very interesting and useful compilation it was, too, dealing with general principles, and work on mouse, baboon and human embryos. Curiously, the symposium organizer was identified as "guest editor", though an associate editor of the journal.

Delays in the publication of regular papers and even of short communications have been rather long, roughly 3-7 months from "acceptance". Dates of "submission" have been included only since April 1986, and from a perusal of these it emerges that the total delay ranges from 8 to 15 months. It is surely important for the journal's future that this be improved. Tables, line drawings and halftone illustrations are all clearly presented; 